\title{
ROLE OF ACADEMIC LIBRARY INFORMATION \& KNOWLEDGE MANAGEMENT AND USER ENGAGEMENT IN INTERLACING CAPABILITY INTO WORKING PRACTICES
}

\author{
Dr. Priyanki R Vyas \\ \& \\ Ms. Kshama Parikh
}

\begin{abstract}
:
The management of knowledge is a powerful tool for any competitive organization. The essence of the organisation is knowledge. In the area of services and services, KM increases productivity, efficiency and effectiveness. Explicit and implicit in nature is knowledge. This paper deals with both the explosion of knowledge or generation, processes and management of knowledge for effective use by end users. With the introduction of ICT, knowledge has gained momentum, changing its direction and dimensions immediately. Since Library is the heart of any institution, Libraries have moved from depositories and warehouses to information centres through the advent of ICT and digital Library technologies. The main focus of this study is on researching the challenges faced by academic Libraries in the management of knowledge.
\end{abstract}

Keywords: Knowledge Management, User Engagement, Academic Library

\section{Introduction}

Effective knowledge management was essential in the emergence of knowledge-based economies. Effective knowledge management has been recognized as a critical ingredient in ensuring a affordable competitive, strategic benefit for organizations. The article shows that the management of knowledge is a key driver for organizational performance and a main tool in the survival, competitiveness and 
profitability of organizations. Therefore, it is crucial for organizations to generate, manage, distribute and use expertise successfully. Concept and practice in the capture, codification and interpretation of information (KM) are influential. Knowledge management (KM) KM might be seen as a Library and information science (LIS) form or as a particular region of expertise. Knowledge in our life has become a main driving force. The significance of knowledge management in academic Libraries is difficult to assess, because of the complex nature of the information. Academic Libraries are crucial at an organization in order to generate information that is equipped with expertise to serve society and enhance understanding.

\section{Knowledge Management as an important tool}

Furthermore, academic Librarians' knowledge and expertise should be seen as the greatest benefit of the Library. The Libraries have always attempted their knowledge in particular, academic Librarians, and they can claim that they're the best qualified knowledge managers in their organization. Academic Libraries have traditional functions in acquiring, processing, distributing and collecting data, in order to deliver end users better services. Moreover, the operation of the academic Library is now more challenging in the increasingly changing environment, needing a new management method. Librarians are social organizations where employees turn user resources into teaching, research and provision of services tasks. A increasing amount of data base operations, process-based knowledge and paperwork are also developed, as are explicit and implicit knowledge in the minds of employees. As the pace of change rises and individuals change employment frequently, there will be multifunctional teams with a limited life cycle operating quickly evolving systems and environments that are data and expertise that used to be concentrate on one individual or process. Now, knowledge management has evolved into a larger business for major global consulting companies like Ernst and Young, Arthur Anderson and Booz-Allen and Hamitton, which seems to give a more desirable option for total quality management (TQM) and company process reengineering projects.

\section{Role of Library Professionals in Knowledge Management}

Information management has long been recognized the domain of Librarians and Libraries. Librarians and information professionals are trained to search, select, purchase, organize, preserve, republish, 
Towards Excellence: An Indexed, Refereed \& Peer Reviewed Journal of Higher Education / Dr. Priyanki Vyas \& Ms. Kshama Parikh / Page 15-26

disseminate and serve information professionals. However, IT and system experts have also considered information management as their domain.

In contemporary technology, the function of Libraries and information centers connects data manufacturers and users, organization, communities, and even nations. Recent developments in telecommunications, computer networks and electronic media are altering Libraries ' way of serving customers through resource networks and disseminating information / knowledge to wide range regardless of distance and place.

The digital revolution has changed the way societies work globally, locally and personally. We have seen certain changes in the field of data in this revolution, particularly in regards to data collection, storage, processing and transmission. These modifications led in Libraries evolving into digital Libraries.

The digital Libraries may be defined as the new way of carrying out the functions of Libraries encompassing new types of information resources, new approaches to acquisition (especially with move towards accessing to different Library collections and their sharing), new methods of storage and preservation, new approaches to classification and cataloguing, intensive use of electronic systems and services.

\section{Librarians can actively play significance role by :}

1. Create knowledge repositories, often in documentary form, which store both expertise and data. These repositories can be divided into 3 classifications:

* External expertise, for example competitive intelligence.

* These include inner structured understanding, including study reports and product-oriented marketing materials, techniques and methods.

* Those who use casual, internal or tacit understanding, such as "know how" debate databases.

2. Improving access and transmission of information. Connectivity, access and transmission are the main priorities. 
Towards Excellence: An Indexed, Refereed \& Peer Reviewed Journal of Higher Education / Dr. Priyanki Vyas \& Ms. Kshama Parikh / Page 15-26

* Improve the environment of knowledge so that its environment leads to the development, transfer and use of knowledge more efficiently. This includes addressing the standards and values of the organization as regards understanding.

* Create awareness on sharing knowledge integrated in user relationship and engagements.

3. Give awards for efforts to the structured knowledge foundation of the organization.

* Implement decision audit programs to assess the use and execution of information by staff in important decisions.

* Recognize the dependency of structures and cultures on efficient knowledge management.

4. Knowledge as an asset to handle and to understand an organization's importance of knowledge.

5. Knowledge Resources Management

Because human information is growing exponentially in many different formats, Libraries need to create resources and share strategies with their task and costs from printed to electronic and digital resources. Libraries must closely analysis their users ' requirements and try to create cooperative environment.

Highlights of Transformation for Knowledge Sharing \& Networking

1. Leadership: Ensure the integration and support of senior leadership

2. Vision and expectations: knowledge sharing

3. Strategy: Designing knowledge-sharing initiatives

4. Incentives: Updating organizational and personnel policies and recognition of champions

The achievements in the sharing of funds and networking of many examples are mainly a consequence of the complete collaboration and involvement of all member Libraries. In this effort, large and major Libraries should take the lead. It is critically essential also to support policies and to support government or parent organisations. All Libraries are shown by experiences, 
Towards Excellence: An Indexed, Refereed \& Peer Reviewed Journal of Higher Education / Dr. Priyanki Vyas \& Ms. Kshama Parikh / Page 15-26

\section{Users Engagement in Knowledge Management -}

In most institutions of higher education in the 21 st century, Users' involvement is a crucial goal. Working to align Library priorities needs a clearer definition of commitment as the idea is understood by others outside Libraries. This will help Library professionals to conceive their job on commitment, student learning, and information literacy as an intangible asset that the organization pursues widely and that the Library can help create by leveraging its job.

User involvement results from two-way interaction-from demands and proof that these requirements have been translated into functionality. Technology adoption is the "last mile" of change management intrinsic in programs of digital transformation. It is not supposed to be the "first mile." The first mile should be the user needs.

There are countless articles on support services and programs aimed at helping learners engage in their own learning and the Library and its resources. Boss, Angell, and Tewell (2015) found increased student contact with colleagues and teachers by evaluating the orientation program. Appleton and Abernethy (2013) narrated partnership with student support services championing the ' You Said-We Did ' strategy to casting learners into the Library enhancement system as partners. 
Towards Excellence: An Indexed, Refereed \& Peer Reviewed Journal of Higher Education / Dr. Priyanki Vyas \& Ms. Kshama Parikh / Page 15-26

V The Library as Engaging Place and Space

Through the Best Practices in the Library, Users Engagement is amazingly possible.

Through the Users Engagement, Library may flourish with extended use of resources and services.

We at IL NU Library offer following services under the banner What's Happening@ILNU Library to occupy our Users in our Library activities.
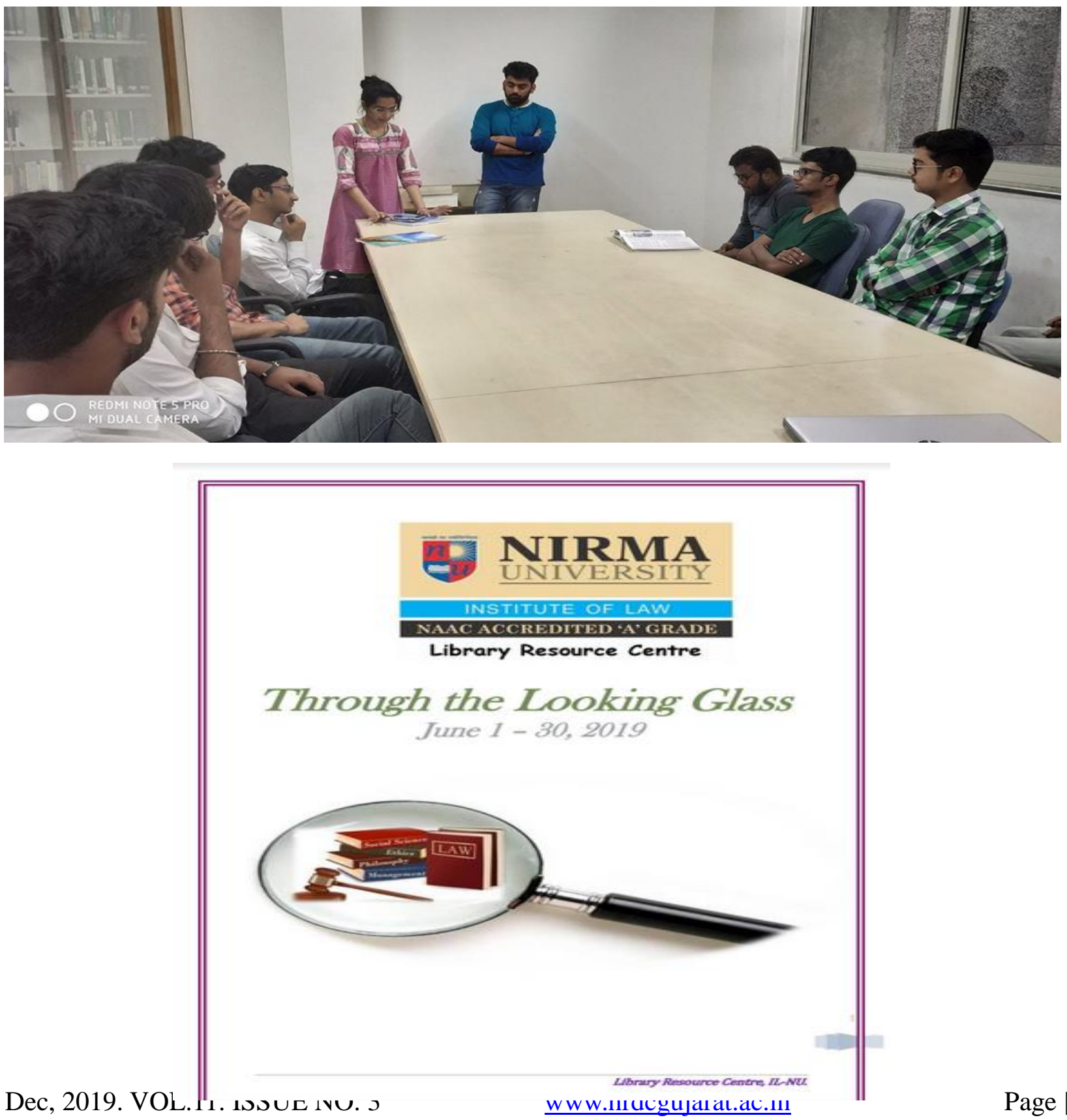
Towards Excellence: An Indexed, Refereed \& Peer Reviewed Journal of Higher Education / Dr. Priyanki Vyas \& Ms. Kshama Parikh / Page 15-26

\section{Through the Looking Glass:}

To Help \& Motivate Users to involve in Collection Development, this Service is started for. It provides you latest Update with your Favorite Subject's Books across the Globe in various Subjects.

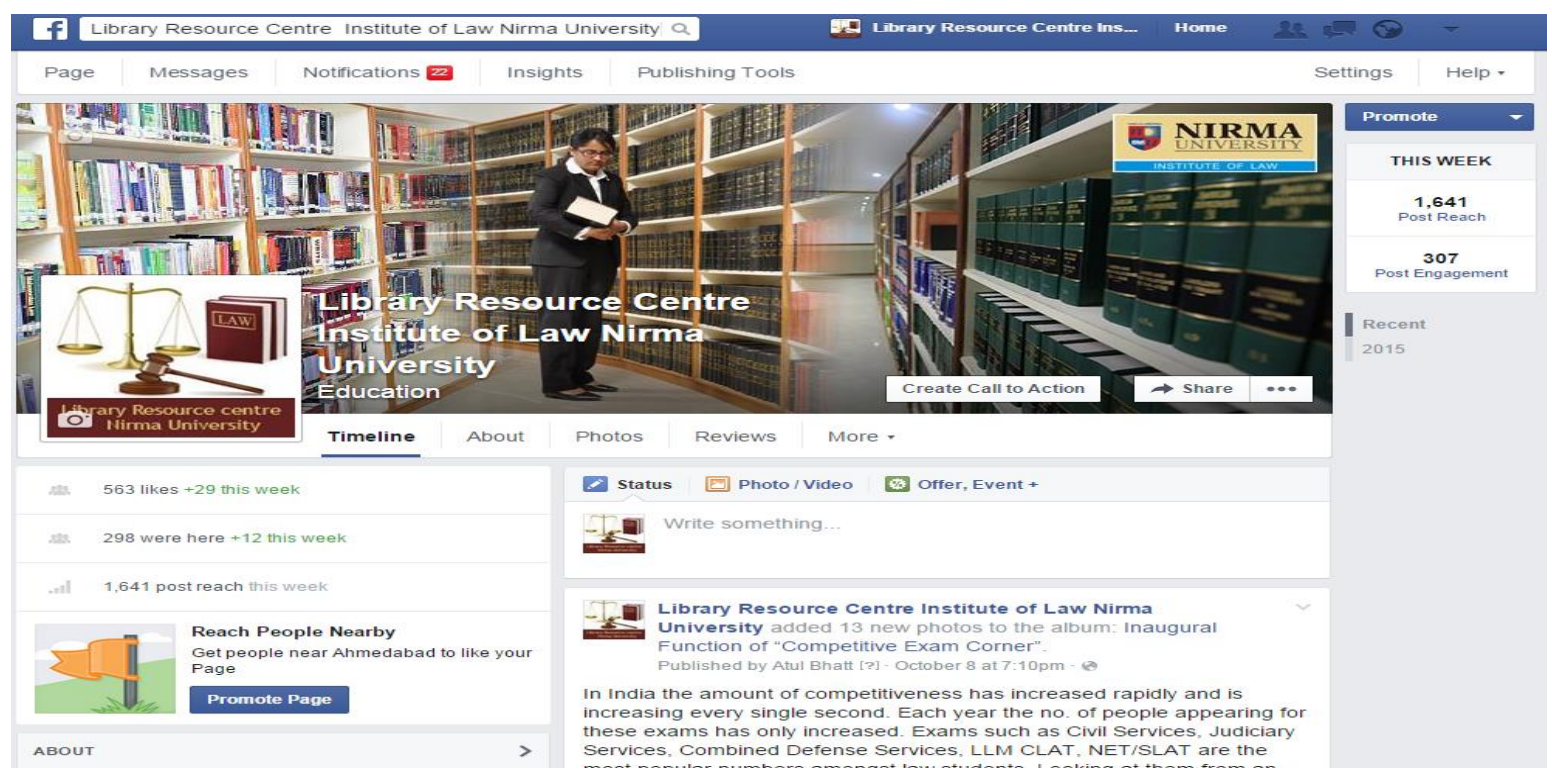

\section{Book Review by the Author/Teacher/Students:}

Best Seller, Interesting, Well Reviewed by prominent People etc. Books are reviewed here among the Users.

"Talk-SHOW" - A dialogue-based discussion sessions: Informal Session with Expert \& Coffee... 
Towards Excellence: An Indexed, Refereed \& Peer Reviewed Journal of Higher Education / Dr. Priyanki Vyas \& Ms. Kshama Parikh / Page 15-26

\section{Books Displays on specific Topic:}

Interesting \& Useful Topics are Selected and Displayed....

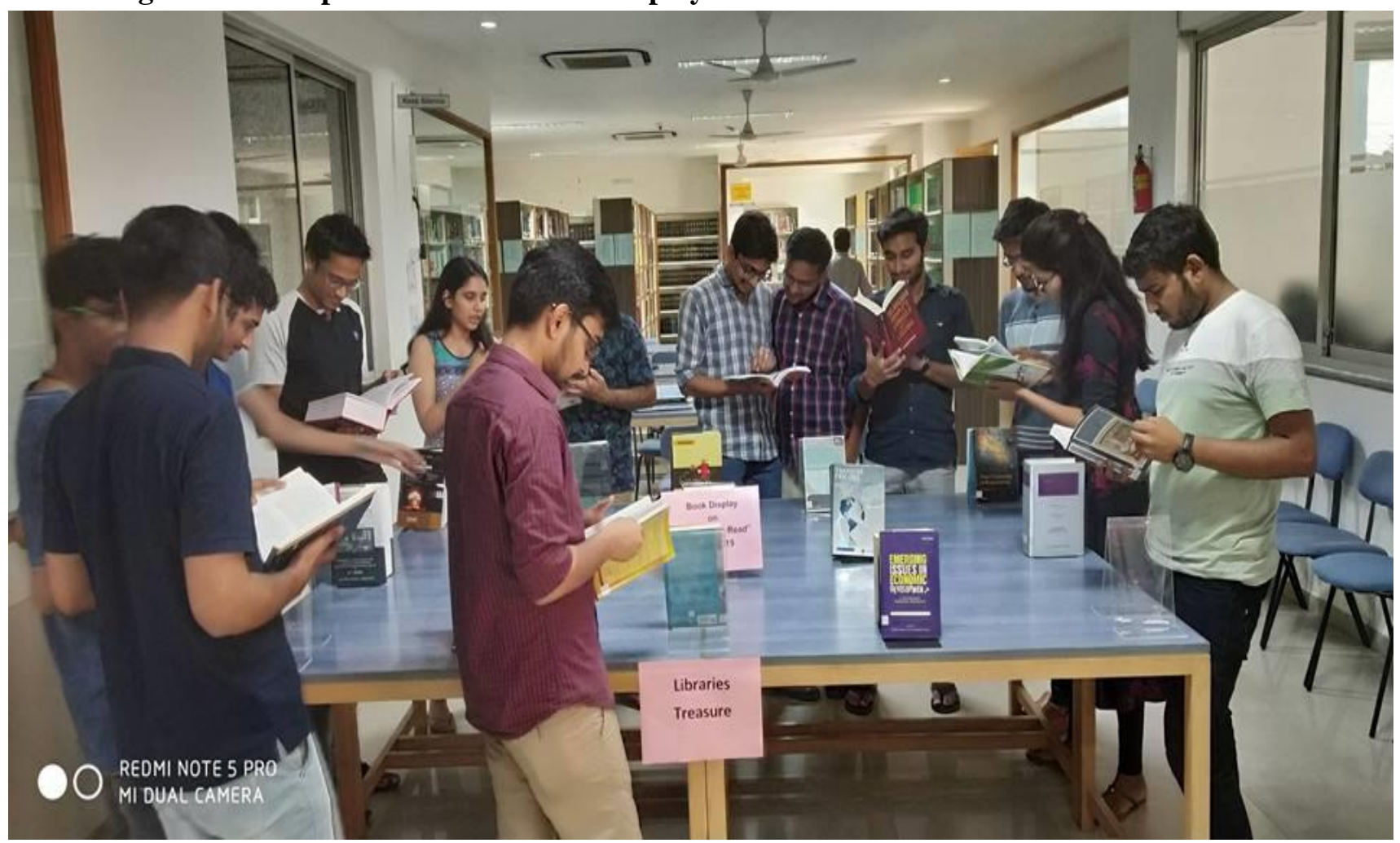

\section{Competitive Exam Corner:}

Especially in India the amount of competitiveness has rapidly and is increasing every single second. We strive to Encourage \& Provide Excellent Collection to Users with Peaceful Environment; this corner is existing to serve this purpose.

\section{Connect us on Social Media!}

We are connecting with our users on FB, Youtube etc. Latest updates they may receive from the latest technology. 


\section{Research Wall}

Faculty, Students and Staff's achievements are highlighted on Research Wall.

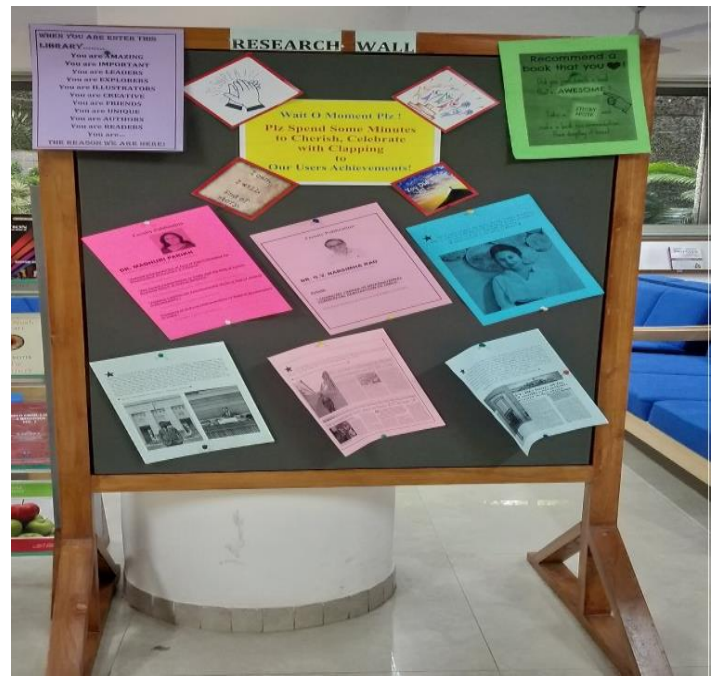

\section{Collection Development:}

Every year we receive handsome budget for the Library. Users play major role in collection development of the Library. Users recommend resources for their research area and Library is growing fantastically with worth usage of each rupee from the Library budget.

So these all are the practices, we do practice to make our Users involve with our Library.

\section{Conclusion}

A leadership committed to knowledge sharing must see knowledge as a strategic asset, develop a clear vision of how people in the organization should behave, and champion that vision. Culture cannot be changed overnight, but organizations can put in place a variety of measures to gradually shift their culture toward becoming more open and collaborative. 
As a knowledge manager, Librarian should be able to organize various pieces of data by systematically collecting books, journals, records, audio-visual aids, computer databases and other reference materials in order to provide Right Knowledge, In Right Place, and At Right Time. They should be able to remove, filter and extract, and disseminate knowledge with users in collecting and analyzing strategic intelligence.

From the creation of human civilization, knowledge is constantly growing. Processes and contexts of information material must be closely managed to maintain and disseminate understanding for value-added development.

KM should be incorporated with the organization's strategic management to build competitiveness. It has always become dynamic in nature with the advent of ICT, which has to be efficiently managed for storage and service.

Library functions as the human knowledge's main storehouse. Using contemporary technology with telecommunications pcs and networking. Librarian acts as the knowledge manager who, regardless of place and distance, classifies, preserves and disseminates knowledge from creator to information seeking society. 
Towards Excellence: An Indexed, Refereed \& Peer Reviewed Journal of Higher Education / Dr. Priyanki Vyas \& Ms. Kshama Parikh / Page 15-26

\section{References}

20. Technology and Library Users: LITA Experts Identify Trends to Watch. (Chicago: LITA, 1999). http://www.lita.org/committe/toptech/trendsmw99.htm Accessed on 7 Oct. 2019.

Chen, Hsinchun. Knowledge Management Systems: A Text Mining Perspective. Tucson, Arizona: University of Arizona. 2001. 18.

Cohen, Suzanne and others. Personalized Electronic Services in the Cornell University Libraries. D-Lib Magazine 6, no.4:1-2. http://www.dlib.org/dlib/april00/mistlebauer/04mistlebauer.html Accessed on 18 Sept. 2019.

Duffy, Jan Duffy. Knowledge Management: To Be or Not to Be? Information Management Journal 34 (1). 2000. 64-67.

Janus, Steffen Soulejman. Becoming a Knowledge-Sharing Organisation: A Handbook for Scaling Up Solutions through Knowledge Capturing and Sharing. World Bank Group. 2016. 23-30.

Liebowitz, Jay. Building Organizational Intelligence: A Knowledge Management Primer. Boca Raton, FL: CRC Press. 1. 2000.

Omotayo, Funmilola Olubunmi. Knowledge Management as an important tool in Organisational Management: A Review of Literature. Library Philosophy and Practice (e-journal).1238. 2015. http://digitalcommons.unl.edu/libphilprac/1238 Accessed on 6 Sept.2019.

Schlak, Tim. Academic Libraries and Engagement: A Critical Contextualization of the Library Discourse on Engagement. The Journal of Academic Librarianship. September 2017. 1-18. 
Towards Excellence: An Indexed, Refereed \& Peer Reviewed Journal of Higher Education / Dr. Priyanki Vyas \& Ms. Kshama Parikh / Page 15-26

Singha, Krishnamati, Shrivastava, V D \& Singha, Gouri. Essence of Knowledge Management in Libraries in Modern Era. $3^{\text {rd }}$ Convention PLANNER -2005, Assam Univ., Silchar. 10-11 November; 2005. 106-111.

Dr. Priyanki R Vyas

Associate Professor

Dept of Library \& Information Science

Dr Babasaheb Ambedkar Open University, Ahmedabad

$\boldsymbol{\&}$

Ms. Kshama Parikh

I/c Librarian, Institute of Law, NIRMA University 